\title{
Resemblance between rhodopsin kinase and S-antigen induced uveitis
}

\author{
ROBERT B. NUSSENBLATT, ${ }^{1}$ HITOSHI SHICHI, ${ }^{2}$ TOICHIRO KUWABARA,${ }^{2}$ \\ STANLEY CEVARIO,' AND IGAL GERY ${ }^{2}$ \\ From the ${ }^{1}$ Clinical Branch and ${ }^{2}$ Laboratory for Vision Research, National Eye Institute, \\ National Institutes of Health, Department of Health and Human Services, Bethesda, Maryland 20205, USA
}

SUMmaRY The retinal S-antigen ( $\mathrm{S}-\mathrm{Ag}$ ) has been shown to induce uveitis effectively in subhuman primates, and lymphocytes from patients with certain uveitic conditions show cell-mediated responses to this antigen. Rhodopsin kinase (RK), an enzyme probably unique to the mammalian eye, is reported here to resemble the retinal S-Ag in its capacity to induce uveitis in experimental animals. A histological comparison of rat eyes taken 2 and 3 weeks after immunisation with either RK or S-Ag reveals essentially identical pathological alterations. Ocular inflammation is seen in both the anterior and posterior portion of the globe. Areas of focal degeneration of the photoreceptor layer, from which both the S-Ag and RK are extracted, could be seen in both RK and S-Ag immunised animals. Cells from draining lymph nodes of both groups responded by increased thymidine incorporation when cultured in the presence of either RK or S-Ag. In addition antibodies directed against the $\mathrm{S}-\mathrm{Ag}$ were detected in both groups. These findings, in addition to the biochemical similarities of these preparations, reported elsewhere, would strongly suggest that RK and S-Ag are one and the same. The identification of potentially uveitogenic ocular antigens could help to reclassify uveitic entities that at present have clinically similar courses.

Uveitis is one of the most frustrating entities for the ophthalmologist to care for. Evidence is accumulating that various aetiological and immune factors seem to be at work. A variety of HLA associations ${ }^{1-3}$ underscore the varied and complex nature of the immune response resulting in this disease. The notion that endogenous dysregulation may be a prime problem in the disease is mounting, with reports of alterations in suppressor cell function and in-vitro cell-mediated immune responses to a purified retinal antigen, the S-antigen. ${ }^{45}$

The effectiveness of the retinal S-antigen in inducing a reproducible animal model of autoimmune intraocular disease has been repeatedly shown ${ }^{67}$ since its purification by the groups of Wacker ${ }^{8}$ and Faure. ${ }^{9}$ Recently we demonstrated its capacity to induce a bilateral uveitis in subhuman primates, which has the characteristics of many posterior uveitic syndromes. ${ }^{10}$ The S-antigen has been found in all mammalian retinae to date, and its physical characteristics

Correspondence to Robert Nussenblatt, MD, Building 10, Room 10N307. National Institutes of Health, Bethesda, Maryland 20205. USA. reported. ${ }^{11}$ The identity of the S-antigen and its possible physiological role in the retina has remained open to speculation. The suggestions that the Santigen might be the retinol binding protein, ${ }^{11}$ or phosphodiesterase ${ }^{12}$ could not be supported by experiment (J. P. Faure, personal communication). A recent study by one of us (H.S., in preparation ) has provided data suggesting that the S-antigen is rhodopsin kinase (RK). This proposal is based on the following: (1) preparations of RK react with specific antibodies to the S-antigen in a pattern identical to that of the specific antigen; (2) preparations of the S-antigen contain specific enzymatic activity of rhodopsin phosphorylation; (3) the RK activity is inhibited by specific antibodies to S-antigen.

We report here that purified RK resembles Santigen in its capacity to induce uveitis in experimental animals. In addition, the cross-reactivity between S-antigen and RK was further established by using numerous immunological tests. The identification of potentially uveitogenic antigens would be an important step in the understanding of ocular inflammatory mechanisms. 


\section{Materials and methods}

Female inbred Lewis rats ( 7 weeks old, M.A. Bioproducts, Walkersville, MD) were used in all experiments. Two groups of 4 rats each were immunised with $30 \mu \mathrm{g}$ of either bovine S-antigen, prepared according to Wacker et al. " or RK prepared as described elsewhere. ${ }^{13}$ Both the S-antigen and RK preparations were found to be homogeneous and migrated as a single band during electrophoresis in sodium dodecyl sulphate-containing polyacrylamide gel (data not shown). Both proteins were emulsified $(1: 1)$ in complete Freund's adjuvant (CFA, GIBCO, Grand Island, NY), enriched with $2 \mathrm{mg} / \mathrm{ml}$ of killed Mycobacterium tuberculosis H37RV (Eli Lilly Co., Indianapolis, IN). A control group of 3 rats received the above CFA emulsified with saline. The emulsions were injected into both hind footpads in a total volume of $0.2 \mathrm{ml}$ per rat.

Animals were killed 14 or 21 days after immunisation. Blood samples were collected by cardiac puncture and the rats were killed with ether. Popliteal lymph nodes were removed aseptically and lymphocyte cultures were prepared as described elsewhere. ${ }^{7}$ The cultures, in triplicate, consisted of $3 \times 10^{5}$ cells in $0 \cdot 2 \mathrm{ml}$ Roswell Park Memorial Institute (RPMI) 1640 medium with HEPES (M.A. Bioproducts) supplemented with $10 \%$ heat inactivated human serum. Antigens and mitogens were added in aliquots of 10 $\mu l$ and included S-antigen, RK, purified protein derivative (PPD, Connaught Laboratories, Toronto, Canada), and concanavallin-A (con-A, Calbiochem, San Diego, CA). The cultures were incubated for a total of 4 days and pulsed for the last 16 hours with 1 $\mu \mathrm{Ci} /$ well of ${ }^{3} \mathrm{H}$ thymidine (Amersham, Arlington Heights, IL). The cultures were harvested on a MASH II harvester and the incorporated radioactivity was measured by a Beckman scintillation counter. Results are presented by both counts per minute (cpm) and stimulation index (SI), derived as described elsewhere. ${ }^{?}$

Serum antibodies to S-antigen were titrated by passive haemagglutination with formalinised sheep red blood cells (SRBC). ${ }^{14}$ The SRBC were sensitised with S-antigen at $200 \mu \mathrm{g} / \mathrm{ml}$ and the tests were carried out in U-shaped microplates (Cooke Laboratories, Alexandria, VA).

Eyes of experimental rats, enucleated when they were killed, were fixed in $2.5 \%$ glutaraldehyde, embedded in glycol methacrylate, and sections cut at $3 \mu \mathrm{m}$ were stained with haematoxylin and eosin.

\section{Results}

The treated rats were examined for their immune responses and pathological ocular changes 14 or 21 days after immunisation. A striking similarity was found between the animals injected with S-antigen and RK; both groups showed clinical evidence of a severe ocular inflammatory response and immune

Table 1 Mitotic responses of lymphocytes from Lewis rats immunised against $S$-antigen $(S$ - $A g$ ), rhodopsin kinase (RK) or complete Freund's adjuvant (CFA) alone

\begin{tabular}{|c|c|c|c|c|c|c|c|c|}
\hline \multirow[t]{3}{*}{ Rat } & \multirow{3}{*}{$\begin{array}{l}\text { Immunising } \\
\text { material }\end{array}$} & \multicolumn{7}{|c|}{ Stimulant in culture $\mu / \mathrm{ml}$} \\
\hline & & \multirow[b]{2}{*}{ None } & \multicolumn{2}{|c|}{ Rhodopsin kinase } & \multicolumn{2}{|l|}{ S-antigen } & \multirow{2}{*}{$\frac{P P D}{10}$} & \multirow{2}{*}{$\frac{\text { Con-A }}{5}$} \\
\hline & & & $2 \cdot 5$ & 1 & $2 \cdot 5$ & $l$ & & \\
\hline 1 & $\mathrm{RK}+\mathrm{CFA}$ & $48 \pm 10$ & $\begin{array}{c}389 \pm 46^{*} \\
(8 \cdot 1)\end{array}$ & $\begin{array}{c}326 \pm 37 \\
(6 \cdot 8)\end{array}$ & $\begin{array}{c}1017 \pm 516 \\
(21 \cdot 2)\end{array}$ & $\begin{array}{l}829 \pm 156 \\
(17 \cdot 3)\end{array}$ & $\begin{array}{l}828 \pm 415 \\
(17 \cdot 3)\end{array}$ & $\begin{array}{c}152591 \pm 5593 \\
(3179)\end{array}$ \\
\hline 2 & $\mathrm{RK}+\mathrm{CFA}$ & $197 \pm 20$ & $\begin{array}{c}804 \pm 284 \\
(4 \cdot 1)\end{array}$ & $\begin{array}{c}1419 \pm 382 \\
(7 \cdot 2)\end{array}$ & $\begin{array}{c}5415 \pm 1590 \\
(27 \cdot 5)\end{array}$ & $\begin{array}{c}8787 \pm 1489 \\
(44 \cdot 6)\end{array}$ & $\begin{array}{l}5914 \pm 1046 \\
(30 \cdot 0)\end{array}$ & $\begin{array}{c}76973 \pm 9271 \\
(390 \cdot 7)\end{array}$ \\
\hline 3 & S-Ag+CFA & $26 \pm 3$ & $\begin{array}{c}150 \pm 27 \\
(5 \cdot 8)\end{array}$ & $\begin{array}{l}52 \pm 23 \\
(2 \cdot 0)\end{array}$ & $\begin{array}{l}561 \pm 153 \\
(21.6)\end{array}$ & $\begin{array}{c}204 \pm 72 \\
(7 \cdot 9)\end{array}$ & $\begin{array}{c}137 \pm 58 \\
(5 \cdot 3)\end{array}$ & $\begin{array}{l}98682 \pm 1952 \\
(3795 \cdot 5)\end{array}$ \\
\hline 4 & $S-A g+C F A$ & $81 \pm 25$ & $\begin{array}{c}308 \pm 96 \\
(3 \cdot 8)\end{array}$ & $\begin{array}{c}370 \pm 135 \\
(4 \cdot 6)\end{array}$ & $\begin{array}{c}286 \pm 74 \\
(3 \cdot 5)\end{array}$ & $\begin{array}{c}424 \pm 21 \\
(5 \cdot 2)\end{array}$ & $\begin{array}{c}229 \pm 155 \\
(2 \cdot 8)\end{array}$ & $\begin{array}{c}84224 \pm 2265 \\
(1039 \cdot 8)\end{array}$ \\
\hline 5 & S-Ag+CFA & $1575 \pm 420$ & $\begin{array}{c}3196 \pm 335 \\
(2 \cdot 0)\end{array}$ & $\begin{array}{c}3115 \pm 820 \\
(2 \cdot 0)\end{array}$ & $\begin{array}{c}4866 \pm 518 \\
(3 \cdot 1)\end{array}$ & $\begin{array}{c}5764 \pm 206 \\
(3 \cdot 7)\end{array}$ & $\begin{array}{c}17550 \pm 3888 \\
(11 \cdot 1)\end{array}$ & $\begin{array}{c}104895 \pm 5692 \\
(66 \cdot 6)\end{array}$ \\
\hline 6 & $\mathrm{~S}-\mathrm{Ag}+\mathrm{CFA}$ & $2751 \pm 79$ & $\begin{array}{c}21066 \pm 1587 \\
(7 \cdot 7)\end{array}$ & $\begin{array}{c}14640 \pm 1093 \\
(5 \cdot 3)\end{array}$ & $\begin{array}{c}51423 \pm 9646 \\
(18 \cdot 7)\end{array}$ & $\begin{array}{c}27819 \pm 219 \\
(10 \cdot 1)\end{array}$ & $\begin{array}{c}46631 \pm 4014 \\
(17 \cdot 0)\end{array}$ & $\begin{array}{c}21554 \pm 1774 \\
(7 \cdot 8)\end{array}$ \\
\hline 7 & $\mathbf{R K}+\mathbf{C F A}$ & $220 \pm 36$ & $\begin{array}{c}946 \pm 57 \\
(4 \cdot 3)\end{array}$ & $\begin{array}{c}653 \pm 87 \\
(3 \cdot 0)\end{array}$ & $\begin{array}{c}1953.551 \\
(8.9)\end{array}$ & $\begin{array}{c}1030 \pm 232 \\
(4 \cdot 7)\end{array}$ & $\begin{array}{c}4422 \pm 1324 \\
(20 \cdot 1)\end{array}$ & $\begin{array}{c}144.377 \pm 4599 \\
(656 \cdot 3)\end{array}$ \\
\hline 8 & $\mathbf{R K}+\mathbf{C F A}$ & $543 \pm 120$ & $\begin{array}{c}1105 \pm 215 \\
(2 \cdot 0)\end{array}$ & $\begin{array}{c}1378 \pm 18 \\
(2 \cdot 5)\end{array}$ & $\begin{array}{c}3583 \pm 94 \\
(6 \cdot 6)\end{array}$ & $\begin{array}{c}2982 \pm 44 \\
(5 \cdot 5)\end{array}$ & $\begin{array}{c}17913 \pm 3195 \\
(33 \cdot 0)\end{array}$ & $\begin{array}{c}85977 \pm 6551 \\
(158 \cdot 3)\end{array}$ \\
\hline 9 & CFA only & $462 \pm 88$ & $\begin{array}{c}567 \pm 292 \\
(1 \cdot 2)\end{array}$ & $\begin{array}{c}388 \pm 110 \\
(0 \cdot 8)\end{array}$ & $\begin{array}{c}777 \pm 235 \\
(1 \cdot 7)\end{array}$ & $\begin{array}{c}722 \pm 192 \\
(1 \cdot 6)\end{array}$ & $\begin{array}{c}4668 \pm 98 \\
(10 \cdot 1)\end{array}$ & $\begin{array}{c}40194 \pm 2734 \\
(87 \cdot 0)\end{array}$ \\
\hline 10 & CFA only & $1739 \pm 231$ & $\begin{array}{c}2119 \pm 110 \\
(1 \cdot 2)\end{array}$ & $\begin{array}{c}2393 \pm 480 \\
(1 \cdot 4)\end{array}$ & $\begin{array}{c}2266 \pm 446 \\
(1 \cdot 3)\end{array}$ & $\begin{array}{c}1774 \pm 63 \\
(1 \cdot 0)\end{array}$ & $\begin{array}{c}15688 \pm 842 \\
(9 \cdot 0)\end{array}$ & $\begin{array}{c}68787 \pm 4948 \\
(39 \cdot 6)\end{array}$ \\
\hline 11 & CFA only & $3383 \pm 940$ & $\begin{array}{c}1838 \pm 929 \\
(0 \cdot 5)\end{array}$ & $\begin{array}{c}2403 \pm 130 \\
(0 \cdot 7)\end{array}$ & $\begin{array}{c}3204 \pm 677 \\
(1 \cdot 0)\end{array}$ & $\begin{array}{c}3824 \pm 1234 \\
(1 \cdot 1)\end{array}$ & $\begin{array}{c}26036 \pm 867 \\
(7 \cdot 7)\end{array}$ & $\begin{array}{c}64834 \pm 4547 \\
(19 \cdot 2)\end{array}$ \\
\hline
\end{tabular}

*Values are mean cpm $\pm \mathrm{SE}$; in parentheses, stimulation index. 

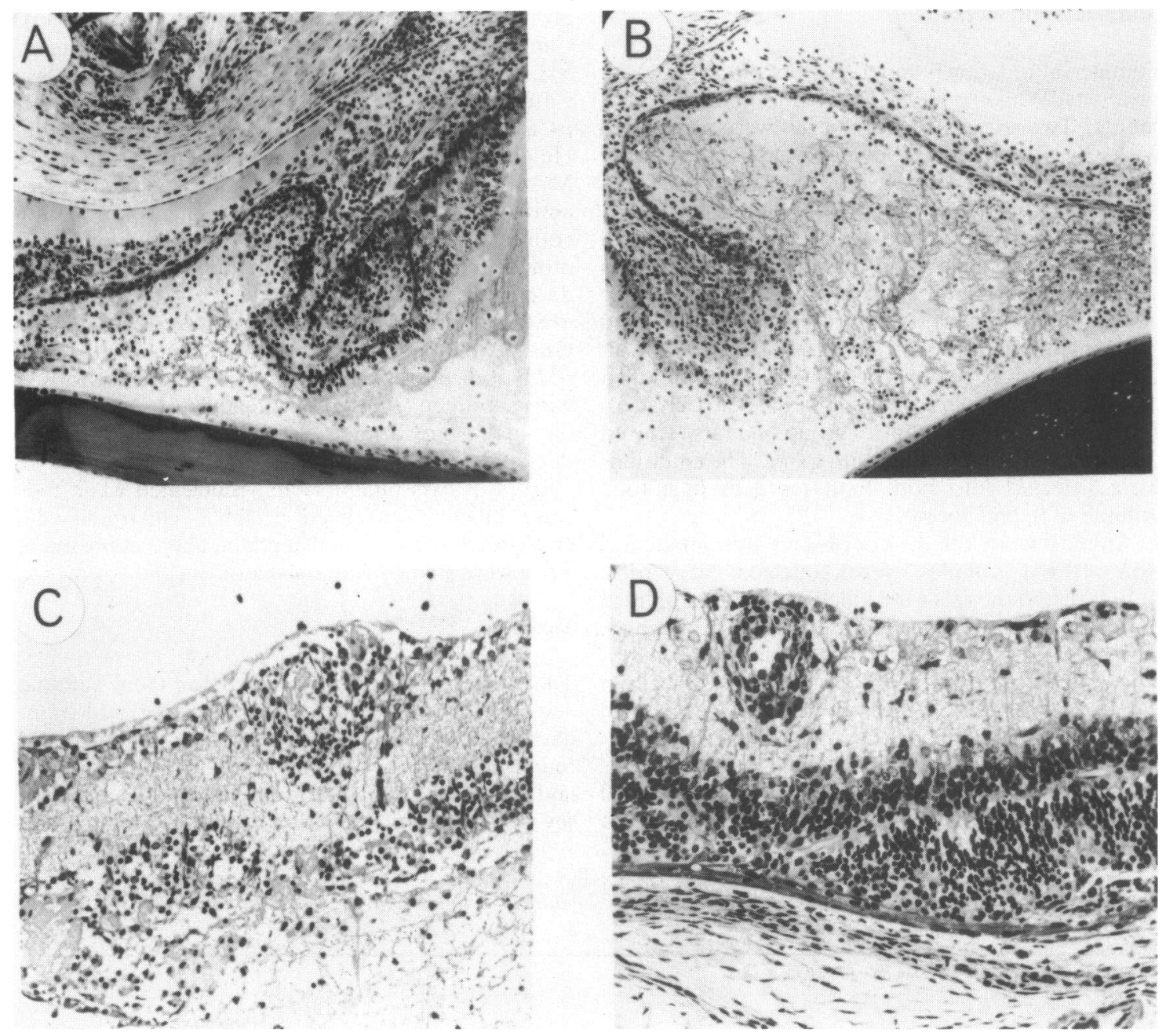

Fig. 1 Two weeks after immunisation. A. Anterior segment in S-Ag induced uveitis and B in RK induced uveitis. Note heavy round-cell infiltrate with fibrin present in both anterior and posterior chambers $(\times 84)$. C. Posterior segment in $S$ - $A g$ induced uveitis and $\mathrm{D}$ in $R K$ induced uveitis. Note perivascular collection of cells, drop-out of photoreceptor region, and subretinal collection of inflammatory cells with fibrin $(\times 154)$.

responses to either one of the antigens. Cells from draining lymph nodes of both groups showed increased thymidine incorporation when cultured in the presence of either RK or S-antigen as compared to the responses of cells from control rats (Table 1). By the Wilcoxen rank sum test both the S-antigen and rhodopsin kinase groups of animals had significantly higher proliferative responses than the group immunised with CFA alone. The specificity of the responses to the retinal preparations was further supported by the finding that cells from all animals reacted well to PPD, an integral component of CFA, and to the polyclonal mitogen con-A.
The similarity between the rats immunised against S-antigen or RK was also exhibited when sera were titrated for antibodies to S-antigen (Table 2). No haemagglutinating antibodies were detected in any of the sera obtained 14 days after immunisation, while all sera collected at the 21-day interval showed positive responses. Again, identical levels of antibodies to S-antigen were found in sera of rats immunised with either this antigen or RK.

A resemblance between the effects of S-antigen and RK was evident when the uveitogenic effects of the two preparations were compared. Examples of the pathological changes seen in the S-antigen and 

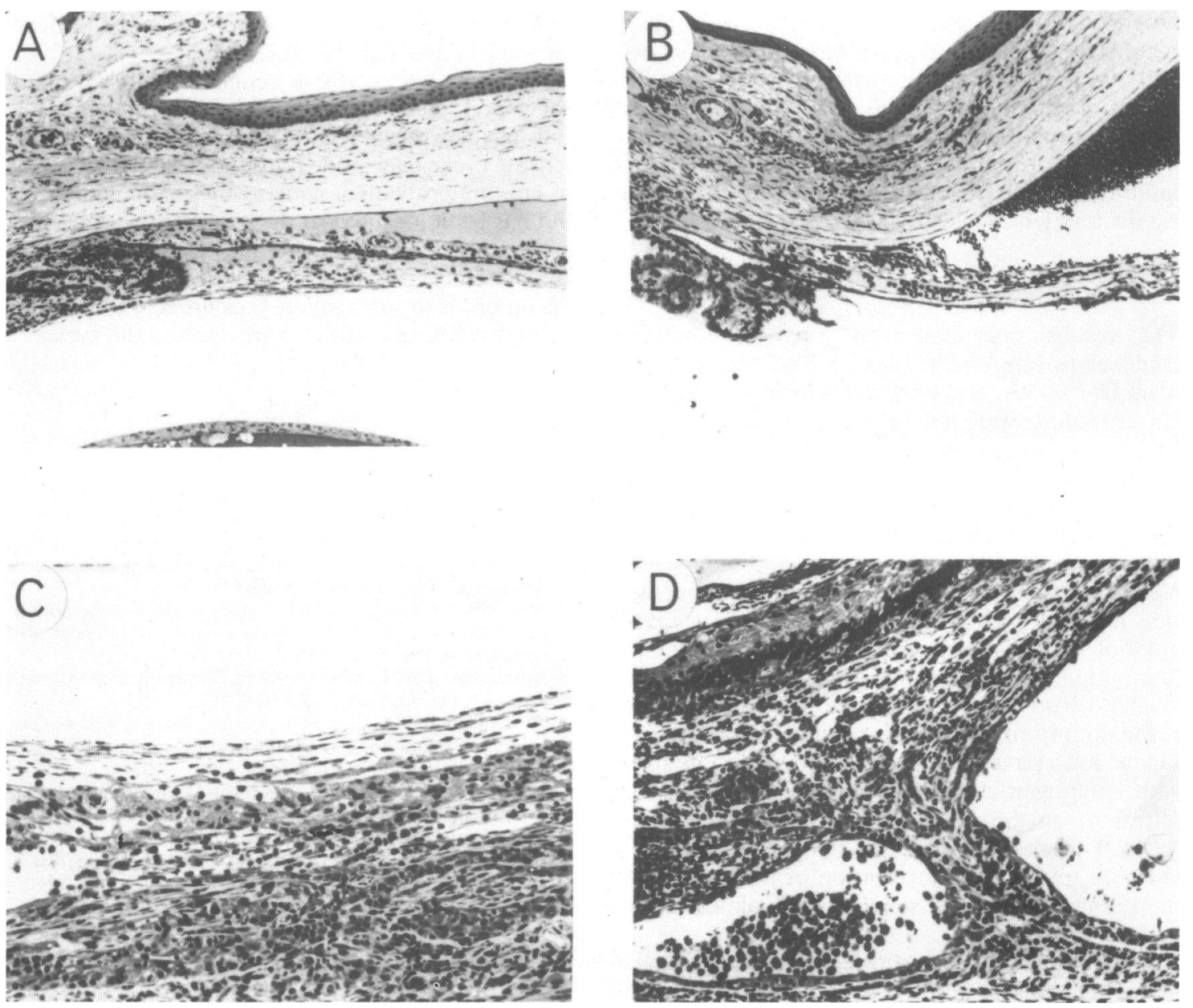

Fig. 2 Three weeks after immunisation. A. Anterior segment in S-Ag induced uveitis and B in RK induced uveitis. Cellular response is considerably decreased with blood and/or fibrin remaining in the anterior chamber $(\times 78)$. C. Posterior segment of $S$-Ag induced uveitis and $\mathrm{D}$ of $R K$ induced uveitis. Note marked degeneration of retina with RPE activation as well as subretinal gliotic changes ( $\times 143)$.

Table 2 Comparison of serological, cell mediated, and histological responses of rhodopsin kinase $(R K)$ and $S$-antigen $(S-A g)$ immunised Lewis rats

\begin{tabular}{llllll}
\hline Rat & $\begin{array}{l}\text { Immunising } \\
\text { material }\end{array}$ & $\begin{array}{l}\text { No. of weeks } \\
\text { post } \\
\text { immunisation }\end{array}$ & $\begin{array}{l}\text { Haemagglutina- } \\
\text { tion titre against } \\
\text { S-Ag }\end{array}$ & $\begin{array}{l}\text { Histology } \\
\text { (grade 0-4)* }\end{array}$ & $\begin{array}{l}\text { Cell } \\
\text { responses } \\
\text { to S-Ag }\end{array}$ \\
\hline 1 & RK+CFA & 2 & $<1: 10$ & 4 & $21 \cdot 2$ \\
2 & RK+CFA & 2 & $<1: 10$ & 4 & $27 \cdot 5$ \\
3 & S-Ag+CFA & 2 & $<1: 10$ & 4 & $21 \cdot 6$ \\
4 & S-Ag+CFA & 2 & $<1: 10$ & 4 & $3 \cdot 5$ \\
5 & S-Ag+CFA & 3 & $1: 160$ & 4 & $3 \cdot 1$ \\
6 & S-Ag+CFA & 3 & $1: 40$ & 4 & $18 \cdot 7$ \\
7 & RK+CFA & 3 & $1: 160$ & 4 & $8 \cdot 9$ \\
8 & RK+CFA & 3 & $1: 40$ & 4 & $6 \cdot 6$ \\
\hline
\end{tabular}

*Graded on a scale from $0-4 . "$

+Stimulation index. rhodopsin kinase groups of rats 14 days after immunisation are shown in Fig. 1. Similar alterations were seen in both groups. All eyes had numerous polymorphonuclear cells, lymphocytes, and histiocytes in the anterior and posterior chambers, with round-cell infiltrates in the iris and ciliary body. Posteriorly the retinae were usually detached, with serum, fibrin, and inflammatory cells in the subretinal space. The disorganised retinae showed a disappearance of the photoreceptor cell layer and a mild perivascular infiltrate. There was evidence of retinal pigment epithelium activation. The posterior choroid was in general only mildly infiltrated.

The pathological alterations evident 3 weeks after immunisation are seen in Fig. 2 . In both groups the 
anterior structures were less infiltrated with inflammatory cells. The retina consisted of many glial cells and was thin, with inflammatory cells evident. The retinal pigment epithelium showed evidence of marked proliferation in several areas. The optic nerves were atrophic (not shown), with again a mild infiltration of the choroid noted. Both groups had cataractous lenses.

\section{Discussion}

The results presented here provide additional evidence to support the idea that S-antigen may be identified as RK. Since the preparations used in the current studies were homogeneous, it was reasonable to assume that the striking similarity between the preparations of S-antigen and RK were not due to any contaminants. Histological examination of the uveitic eyes at 2 and 3 weeks after immunisation showed that the alterations induced by these 2 proteins were essentially identical. Thus at the antigen concentration injected both preparations produced a severe anterior and posterior uveitis at 2 weeks after immunisation. Significantly, both groups showed a localised drop-out of the photoreceptor region, which is the area from which both S-antigen and rhodopsin kinase are extracted. This was also seen in monkeys with S-antigen-induced uveitis. ${ }^{10}$ Choroidal infiltration, on the other hand, was relatively mild. After 3 weeks the residual changes appear more localised to the posterior portion of the globe, with the retina becoming in some animals almost a glial band.

Immunological testing showed that the 2 groups of immunised rats responded in similar fashion. Both groups' lymphocytes responded in culture to the $\mathrm{S}-\mathrm{Ag}$ and RK preparations. The in-vitro responses of all $\mathrm{S}-\mathrm{Ag}$ and RK immunised animals to the S-Ag appeared better than the reactions to the RK. This could be attributed to the presence of small quantities of glycerol in the RK preparation, which protects the enzymatic activity of the material. In addition to the similarity in the cellular response rats immunised with $\mathrm{RK}$ were identical with those injected with $\mathrm{S}-\mathrm{Ag}$ in production of specific antibodies.

Newer experimental procedures are providing urgently needed information concerning the role of the immune system in ocular disease. The identification of a specific ocular antigen towards which the immune response is directed helps to fulfil one of the classic 'postulates' set by Witebsky and associates ${ }^{15}$ to prove the role of autoimmunity in disease aetiology. The presumptive identification reported here may soon be used in practical laboratory techniques for the patient. The testing of various immune parameters in uveitis patients could help reclassify the uveitic entities that at present appear to be curiously the same in their clinical presentation.

The exact role of RK in ocular metabolism is still not clear. Liebman and Pugh have suggested that RK may quench the ability of bleaching rhodopsin to activate cyclic nucleotide phosphodiesterase ${ }^{16} \mathrm{RK}$ is an enzyme probably unique to the mammalian eye, and has been localised to the external (cytoplasmic) surface of the rod disk membrane.$^{17}$ Further immunological testing in animals and in man is currently under way in order to substantiate conclusively the supposition that RK and the S-Ag are one and the same.

\section{References}

1 Brewerton DA. Caffrey M. Nicholls A. Walters D, James DCO. Acute anterior uveitis and HL-A27. Lancet 1973: ii: 994-8.

2 Ohno S, Nakayama E, Sugiura S, Itakura K. Aoki K, and Aizawa M. Specific histocompatibility antigens associated with Behçet's disease. Am J Ophthalmol 1975; 80: 636-41.

3 Nussenblatt RB, and Mittal KK. Iridocyclitis in black Americans: association with HLA B8 suggests an autoimmune aetiology. $\mathrm{Br} J$ Ophthalmol 1981; 65: 329-32.

4 Nussenblatt RB. Cevario SJ, Gery I. Altered suppressor-cell activities in uveitis. Lancet 1980; ii: 722-3.

5 Nussenblatt RB, Gery I, Ballintine EJ, Wacker WB. Cellular immune responsiveness of uveitis patients to retinal S-antigen. Am J Ophthalmol 1980; 89: 173-9.

6 Rao NA. Wacker WB, Marak GE Jr. Experimental allergic uveitis: clinicopathologic features associated with varying doses of S-antigen. Arch Ophthalmol 1979; 97: 1954-8.

7 Nussenblatt RB, Gery I, Wacker WB. Experimental autoimmune uveitis: cellular immune responsiveness. Invest Ophthalmol Visual Sci 1980; 19: 686-90.

8 Wacker WB. Donoso LA. Characterization of the uveitopathic antigen isolated from bovine retina. ARVO abstracts. Supplement to Invest Ophthalmol Visual Sci 1975; suppl: 94.

9 Faure JP, de Kozak Y, Dorey C, Usui M, Tuyen VV. Experimental autoimmune uveo-retinitis. Activity of different antigenic preparations from the retina. ARVO abstracts. Supplement to Invest Ophthalmol Visual Sci 1975; suppl: 94.

10 Nussenblatt RB, Kuwabara T, de Monasterio FM, Wacker WB. S-antigen uveitis in primates. Arch Ophthalmol 1981;99: 1090-2.

11 Wacker WB, Donoso LA, Kalsow CM, Yankeelov JA Jr. Organisciak DT. Experimental allergic uveitis. Isolation, characterization, and localization of a soluble uveitopathogenic antigen from bovine retina. J Immunol 1977; 119: 1949-58.

12 Faure JP, de Kozak Y, Dorey C, Tuyen VV. Activité de différentes preparations antigéniques de la retine dans l'induction de l'uveo-retinite auto-immune expérimentale chez le cobaye. Arch Ophthalmol (Paris) 1977; 37: 47-60.

13 Shichi H, Somers RL. Light-dependent phosphorylation of rhodopsin. Purification and properties of rhodopsin kinase. J Biol Chem 1978; 253: 7040-6.

14 Daniel TM, Stavitsky AB. Passive hemagglutination in study of antigens and antibodies. Methods Med Res 1964; 10: 152-7.

15 Witebsky E, Rose NR, Terplan KI, Paine JR. Chronic thyroiditis and autoimmunization. JAMA 1957; 164: 1439-47.

16 Liebman PA, Pugh EN. The control of phosphodiesterase in rod disk membranes: kinetics, possible mechanisms and significance for vision. Vision Res 1979; 19: 375-80.

17 Shichi H, Somers RL. Distribution of enzymes involved in nucleotide metabolism in the disk and other rod membranes. Photochem Photobiol 1980; 32: 491-5. 